\title{
Risk factors of visceral leishmaniasis: a case control study in north-western Ethiopia
}

\author{
Solomon Yared ${ }^{1,2^{*}}$, Kebede Deribe ${ }^{3,4}$, Araya Gebreselassie ${ }^{2,4}$, Wessenseged Lemma ${ }^{5}$, Essayas Akililu, \\ Oscar D Kirstein ${ }^{6}$, Meshesha Balkew ${ }^{1}$, Alon Warburg ${ }^{6}$, Teshome Gebre-Michael ${ }^{1}$ and Asrat Hailu ${ }^{7}$
}

\begin{abstract}
Background: Visceral leishmaniasis (VL, also called "kala-azar"), is a life threatening neglected tropical infectious disease which mainly affects the poorest of the poor. VL is prevalent in Ethiopia particularly in the northwest of the country. Understanding the risk factors of $\mathrm{VL}$ infection helps in its prevention and control. The aim of the present study was to identify the factors associated with VL.
\end{abstract}

Methods: A case-control study was carried out during the period of January-July 2013 in northwest Ethiopia. Cases and controls were diagnosed using clinical presentation, the rk39 rapid diagnostic test and Direct Agglutination Test (DAT). A total of 283 (84.8\% males versus 15.2\% females) participants were interviewed. 90 cases and 193 controls were involved, matched by age, sex and geographical location with a ratio of 1:2 (case: controls). Univariate and backward multivariate conditional logistic regression were used to identify risk factors of VL.

Results: Elevated odds of VL was associated with goat ownership (OR=6.4; 95\%: confidence interval [Cl]: 1.5-28.4), living in houses with cracked wall $(\mathrm{OR}=6.4 ; 95 \% \mathrm{Cl}$ : 1.6-25.6), increased family size $(\mathrm{OR}=1.3 ; 95 \% \mathrm{Cl}: 1.0-1.8)$ and the number of days spent in the farm field $(\mathrm{OR}=1.1 ; 95 \% \mathrm{Cl}: 1.0-1.2)$. However, daily individual activities around the home and farm fields, mainly sleeping on a bed ( $\mathrm{OR}=0.2 ; 95 \%$ : $\mathrm{Cl} 0.03-0.9)$, sleeping outside the house under a bed net $(\mathrm{OR}=0.1 ; 95 \% \mathrm{Cl}: 0.02-0.36)]$ and smoking plant parts in the house during the night time $(\mathrm{OR}=0.1 ; 95 \% \mathrm{Cl}$ : 0.01-0.6) were associated with decreased odds of being VL case.

Conclusion: Our findings showed that use of bed net and smoke could be helpful for the prevention of VL in the area particularly among individuals who spend most of their time in the farm. VL control effort could be focused on improving housing conditions, such as sealing cracks and crevices inside and outside houses. Further research is warranted to elucidate the role of goats in the transmission of L. donovani, assess the impact of bed nets and the role of the traditional practice of smoking plants.

\section{Background}

Visceral leishmaniasis (VL, also called "kala-azar"), is a life threatening neglected tropical infectious disease which mainly affects the poorest of the poor. VL, like HIV, suppresses the immunity of infected individuals and is fatal if left untreated. It is transmitted from human to human by the bite of female phlebotomine sand flies. More than $90 \%$ of global VL cases occur in six countries: Bangladesh, Brazil, Ethiopia, India, South Sudan and

\footnotetext{
* Correspondence: solyar2005@yahoo.com

${ }^{1}$ Aklilu Lemma Institute of Pathobiology, Addis Ababa University, Addis

Ababa, Ethiopia

${ }^{2}$ Department of Biology, College of Natural Science, Jigjiga University, Jigjiga, Ethiopia

Full list of author information is available at the end of the article
}

Sudan [1]. East Africa is the second largest VL focus in the world affecting several communities in Sudan, South Sudan, Kenya, Uganda, Somalia and Ethiopia [1,2].

VL is prevalent in Ethiopia particularly in the lowlands of the country where it is suitable for breeding habitats of the vectors [3,4]. Annually 3,700-7400 estimated cases occur [5]. It is estimated that 3.2 million people are at risk of VL in Ethiopia [6]. It is endemic in northwest, northeast, southwest and southern parts of the country [4-11]. In recent years, VL has also spread to areas where it was previously non-endemic (Libo-Kemekem and Sheraro) $[6,9,11]$. Seasonal migration of agricultural labourers between endemic and non-endemic regions, combined with biological, environmental and socioeconomic risk factors may be responsible for the spread 
of this disease. Factors such as dog ownership, sleeping under an Acacia tree during the day, sleeping outside at night time and poor housing conditions were identified as increased VL risk in an epidemic area of Libo-Kemkem district, Amhara region [11].

Several VL cases have been reported from Kafta Humera district, northwest Ethiopia since the 1970s [3,6,12]. Anema and Ritmeijer [3] reported that more than 6000 cases were treated in Kafta Humera district from 1997 to 2004. VL outbreak has occurred throughout the Humera lowland since 1995, Mykadra village being one of the hot spots [4]. People who live in settlement areas and migrant workers are the most vulnerable to VL in the endemic region. For instance, from 1997 to 2004 more than $80 \%$ of patients with VL were male migrant workers infected with $L$. donovani who sleep in the farm [3,4]. Kafta Humera and its surrounding areas have significant economic input for the country because cash crops such as sesame, cotton and sorghum are grown at a commercial scale. Due to this, hundreds of thousands of male migrant workers arrive every year in this place during the agricultural season (June-November) [3,13]. The migrant workers are at high risk of acquiring VL as they live and work being exposed to vectors of VL.

Phlebotomus orientalisis a major vector of $L$. donovani in eastern Sudan [14] and it is the most likely vector in northwest Ethiopia $[15,16]$. This vector is mainly associated with cracked vertisols (black cotton soil) and AcaciaBalanite forests [17,18]. P. orientalis is the most predominant species and active during the night time and is more abundant during the dry season in the agricultural field and vicinity of the resettlement village [16]. However, a disease control strategy is still unpractical because the reservoir host and the ecology and behaviour of the vector have not yet been fully explicated. Therefore, identifying the risk factors of visceral leishmaniasis transmission and understanding the knowledge, attitude and practices that affect transmission of $\mathrm{VL}$ is vital to designing appropriate control methods to reduce the burden of cases in the area. The purpose of the present investigation was to assess the knowledge of villagers about kala-azar and to identify the risk factors associated with VL cases using a case-control study.

\section{Methods}

\section{Study area and population}

This study was carried out from the period of January to July 2013 in the western Tigray region, northwest Ethiopia, which borders Eritrea to the north and Sudan to the west. Based on the 2007 national census, Kafta Humera district has a total population of 92,167. Of these, $32.8 \%$ are urban inhabitants while the rest live in semi-urban and rural areas. Kafta Humera has been known as the focus of VL since 1970 [12]. We selected the study area based on recent VL cases diagnosed in Kahsay Abera Hospital, Setit Humera. The study participants are settlers in Adebay village who returned from Sudan in 1993. The communities in Endris/Hagereselam are also settlers who originated from different parts of Tigray region in the 2003 resettlement program. These two localities comprise more than 10,000 individuals. Agriculture comprises the major economic activity of the fertile black cotton soil (vertisol), supporting cultivation of sesame, cotton and sorghum. The region attracts a large number of labourers especially during the weeding and harvesting period with an average of 200,000 workers migrating each year from different parts of Ethiopia and Sudan [19]. Recently VL cases were highly prevalent in resettled communities and male migrant workers. It seems the area is more conducive for the availability of the vector and reservoir host. Cracked vertisol and forests (dominated by Balanites spp.) are more abundant as compared to other areas in the district [18].

In the study area, only Kahsay Abera hospital provides diagnostic and treatment services pertained to VL. Adebay and Hagereselam villages are about 20 and $30 \mathrm{kms}$ from the urban city of Setit Humera respectively. The villages are located at altitude ranges of $500 \mathrm{~m}$-650meters a.s.l. and along coordinates $14^{\circ} 11.47^{\prime} \mathrm{N}$ and longitudes of $36^{\circ}$ $46.07^{\prime} \mathrm{E}$. Temperature reaches an average of $42^{\circ} \mathrm{C}$ between April and June and falls to between 25 and $35^{\circ} \mathrm{C}$ during the months between June and February. The average annual rainfall is $400-650 \mathrm{~mm}$; with July and August receiving the highest amounts and rain is absent between October and April [20].

\section{Research design}

A retrospective case-control study was carried out based on visceral leishmaniasis cases, a total of $1128 \mathrm{VL}$ cases were admitted and treated at Kahsay Abera Hospital from July 2011 to August 2013. These patients came from Setit Humera, Kafta Humera, Welkayit and Tsegede districts of northwest Ethiopia. Only 90 cases were included in the case and control study. VL patients came from Adebay and Endris/Hagereselam locality (administered under Kafta Humera district). Information about patients; i.e., age, sex and place of residence, date of admission, clinical features on admission and outcomes were collected from the registry of the hospital. Information relating to the patients, such as name, age, address, (Tabia/Kebele) is routinely recorded in the Registration Department. Patients were diagnosed by physicians at this Hospital and defined as a person having fever for at least 2 weeks, associated with weight loss and/or splenomegaly and confirmed either parasitologically or by rk39 dipstick test. Most of the case patients were treated before this study began (2011-2013).

For each case we recruited two controls without VL case history from the left or right side of the neighbouring 
house of the VL case. We only recruited cases the most recent one when VL treated more than one occurred in a household.

Each control was matched to the respective case by sex, location, migrant worker and age range $(<5$ years, 5-14 years, 15-39 years, and 40 years of age or older). In case no one matched the criteria, we used the next house. We recruited migrants for case control study individuals living in the area temporarily for agricultural practices. The respondents were interviewed by trained health professionals. Cases and controls responded to the interviews using a structured questionnaire to capture data regarding their demographic and socio economic characteristics (age, gender, occupation, education, time of living in village and family size), house construction material and its condition, domestic animal ownership and their number per house, kinds of animals kept, sleeping habits, use of bed net and individual activity in the agricultural fields. The questionnaire was also comprised of questions relating to the respondents' knowledge, attitudes and common practices towards VL and sand flies. The questionnaires was translated into the local language (Tigrigna) and pre-tested.

\section{Sample size determination}

The sample size was calculated according to dog ownership and we chose the one with higher sample size in the study. Since owning a dog was found to be a risk factor for VL in a previous study in Amhara region [11] where it was found that $37.4 \%$ of controls had dogs. To detect an odds ratio of 2.28 , with $80 \%$ power and $95 \%$ CI and 1:2 cases to control ratio, the final sample size was estimated at 78 cases and 155 controls. Adding 10\% non-response rate the final sample size was 86 cases and 172 controls, with a minimum sample size of 258 .

\section{Direct Agglutination Test (DAT)}

Asymptomatic VL infections usually occur in high endemic areas. However, blood samples were collected from the control groups, which were selected primarily on the basis of the absence of clinical symptoms and had no history of VL. Blood collection was carried out by health professionals recruited to the project. The serum was separated at Setit Humera Health Centre Laboratory and transported in a cool box to Addis Ababa. The serum was diagnosed by DAT at Addis Ababa University, Medical Faculty, Leishmaniasis Research \& Diagnostic Laboratory. Serologic tests were carried out to identify asymptomatic infections among the controls.

DAT is a simple and user friendly test. The estimated sensitivity of DAT was $94 \%$ in Ethiopia [21]. In performing DAT, serum samples were diluted in physiological saline $(0.9 \% \mathrm{NaCl})$ containing $0.8 \% \beta$-mercaptoethanol. Twofold serial dilutions of the sera were made, starting at a dilution of 1:100 and going up to a maximum serum dilution of 1:102,400. Freeze-dried DAT antigen produced by KIT Biomedical Research was reconstituted with physiological saline. $50 \mu \mathrm{L}$ of DAT antigen solution (concentration of $5 \times 10^{7}$ parasites per $\mathrm{ml}$ ) was added to each well containing $50 \mu \mathrm{l}$ of diluted serum. The results were read after 18 hours of incubation at ambient temperature. The cut-off value was established considering the titres obtained in samples from negative controls. Therefore, a sample was considered positive if it had a titre of 1:800 and above.

\section{Ethical statement}

Ethical clearance was obtained from Addis Ababa University, Medical Faculty, Department of Microbiology, Immunology and Parasitology. The study was part and parcel of a larger study on VL transmission dynamics supported by the Bill \& Melinda Gates Foundation: "Studies on the ecology and transmission dynamics of visceral leishmaniasis in Ethiopia". This project obtained ethical approval from the National Ethics Review Board. Support letters were obtained from the western Tigray Zone and Kafta Humera district Health Bureaus. Informed consent was obtained from all cases and controls, for young children under 18 years old, consent was obtained from their parents.

\section{Data analysis}

Data were entered and analyzed by the statistical packages SPSS, release 16 (SPSS Inc., Chicago, IL, USA) and STATA version 13(Stata Corporation, College Station, TX, U.S.A.). For descriptive statistics, frequency, percentage and mean were used. Association between dependent and independent variables were measured by use of Chi-square test. The risk factor data was analyzed by univariate and backward multivariate conditional logistic regression using the age, sex and residence matching. Odd ratio was calculated with $95 \%$ confidence interval for each variable. Variables with $\mathrm{p}<0.10$ in the univariate analyses were consequently tested in multivariable models. All statistical tests were carried out at a significance level of 0.05 .

\section{Results}

\section{Retrospective data}

A total of 1128 (1019 males: 109 females) VL patients were admitted and treated at Kahsay Abera Hospital from the period of July 2011 to August 2013. The diagnoses were based on the patients' history, clinical examinations, parasitological investigations, and/or rk39 dipstick test results. The number of VL cases varied over the seasons, with a peak in January and February (dry season) sharply declined during the wet season (June, July, and August) (Figure 1). Figure 2 shows distribution of VL cases by age and sex. Most of the cases(825) were in the age 


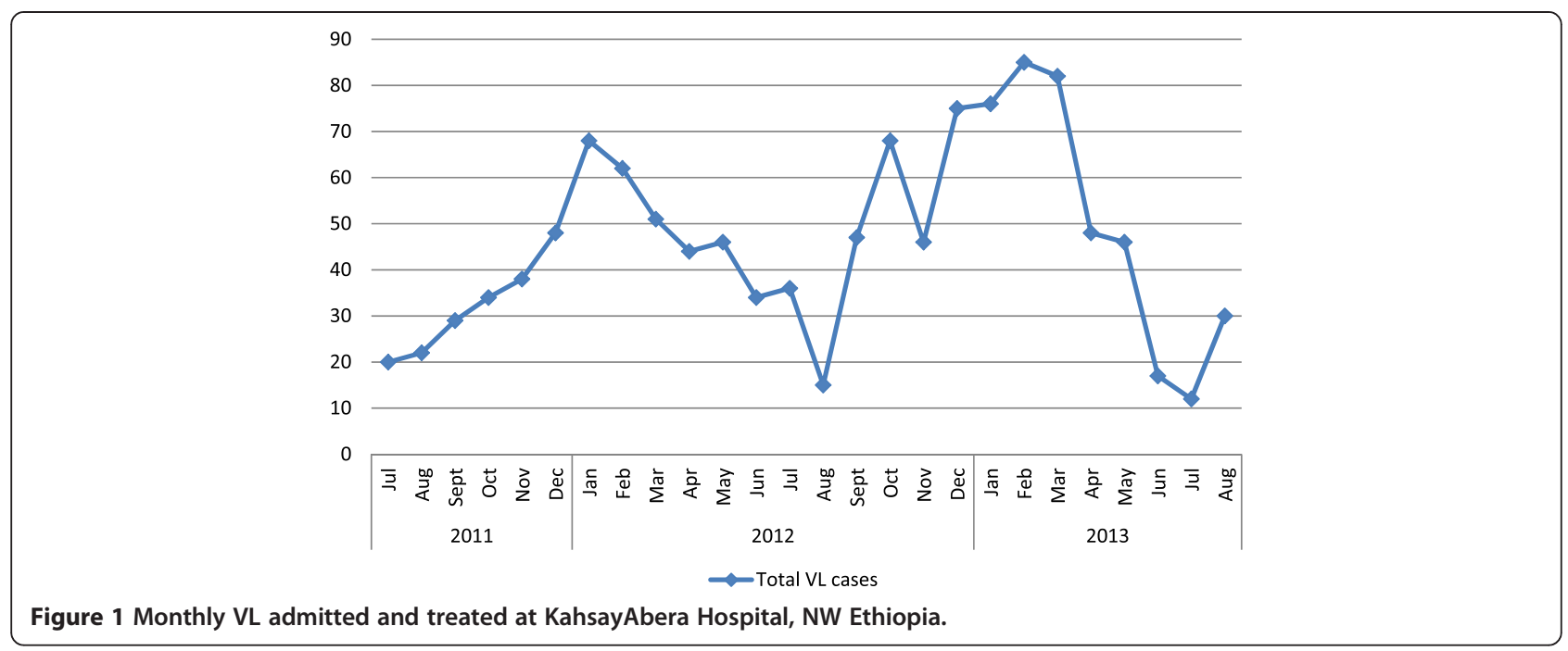

group 15-39 years; the second affected age groups were $5-14$ years (184 cases) followed by $<5$ years (66 cases) and $>=40$ years (53 cases).

\section{Case-control study}

\section{Socio demographic characteristics}

A total of 283 ( $84.8 \%$ males and $15.2 \%$ females) were involved in the study, of which 90 were cases $(85.6 \%$ males versus $14.4 \%$ females) and 193 were controls (84.5\% males and $15.5 \%$ females), matched by age, sex and location (case: control ratio of 1:2). For some of the cases, there were more than two controls. Blood samples were taken from 193 control participants, and tested using DAT; and all samples were found to be negative for $L$. donovani infection. Cases and controls were comparable with respect to many characteristics, except cases tended to have larger family size compared to controls $(\mathrm{p}=0.023)$; controls tended to be from Tigray ethnic groups compared to cases $(\mathrm{p}=0.026)$. In addition, the two groups significantly differed with respect to occupation, educational status and duration slept in the field as described in Table 1.

\section{Knowledge, attitude and practices}

All the 283 of participants were interviewed about their awareness of VL. If a child ( $<15$ years old) was a case or a control, parents were interviewed on behalf of their children. Of the total participants, most (94.0\%) had previously heard about the disease (Table 2).

Concerning attitudes about severity of VL, $64.3 \%$ of the respondents considered $\mathrm{VL}$ as a more severe disease compared to malaria or other diseases (Table 3). The majority $(94.7 \%)$ of the participants preferred modern medicine for treatment of VL. The study participants

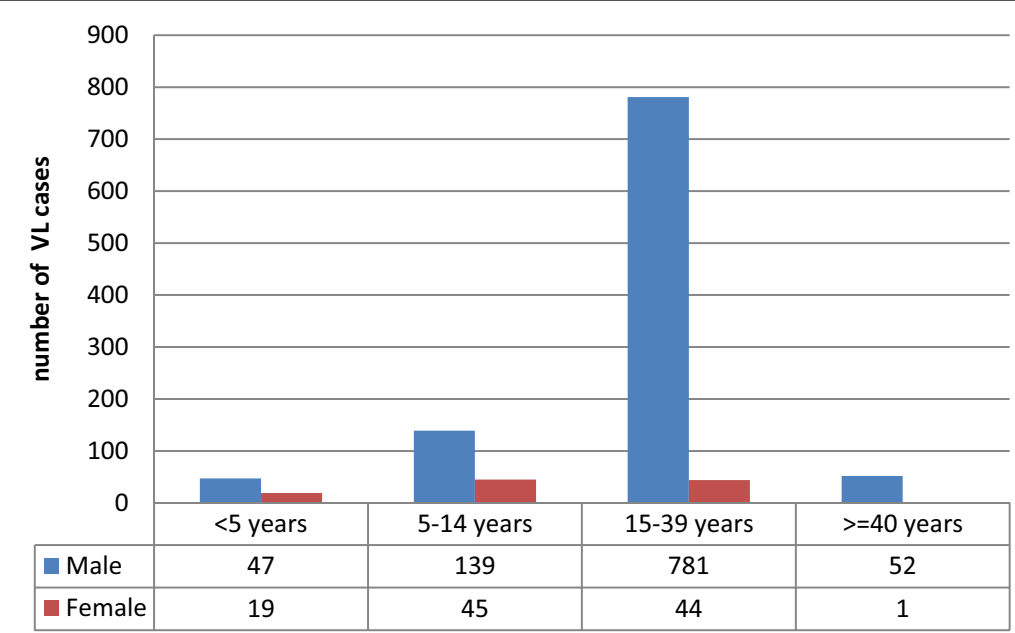

Figure 2 Distribution of VL cases by age and sex, amongst VL patients from KahsayAbera Hospital, Northwest Ethiopia, July 2011- August 2013. 
Table 1 Socio demographic characteristics of participants in case-control study in the visceral leshmaniasis endemic foci of the Adebay and Hagereselam, North -West Ethiopia

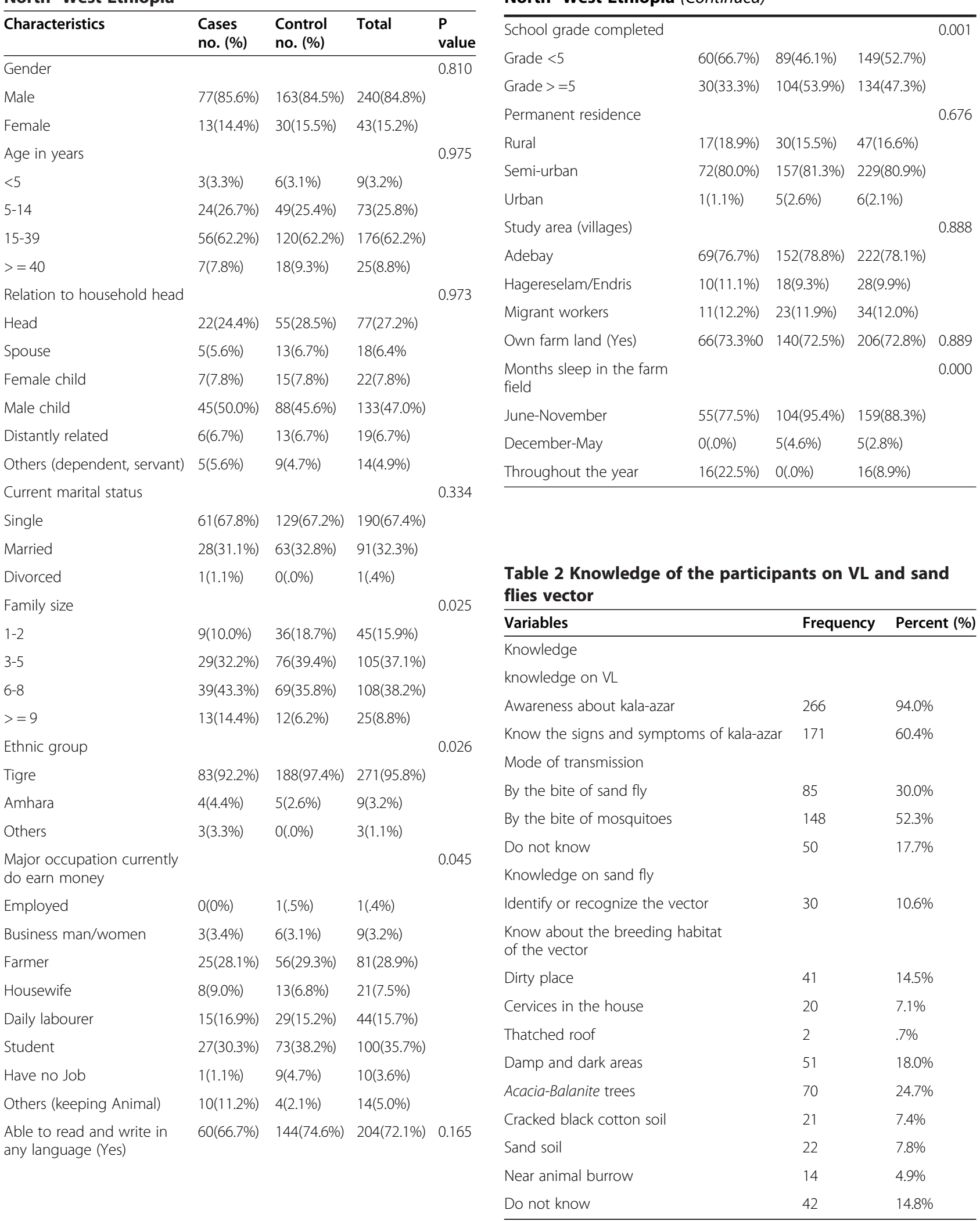

Table 1 Socio demographic characteristics of participants in case-control study in the visceral leshmaniasis endemic foci of the Adebay and Hagereselam, North -West Ethiopia (Continued)

School grade completed 001 676

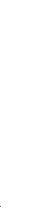

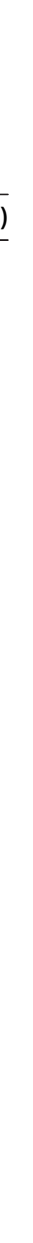


Table 3 Attitude and practice of the participants on VL and sand flies vector

\begin{tabular}{|c|c|c|}
\hline Variables & Frequency & Percent (\%) \\
\hline \multicolumn{3}{|l|}{ Attitude } \\
\hline \multicolumn{3}{|c|}{$\begin{array}{l}\text { The degree of severity of kala-azar } \\
\text { as compared to malaria, kala-azar is }\end{array}$} \\
\hline Very serious & 182 & $64.3 \%$ \\
\hline Serious & 95 & $33.6 \%$ \\
\hline Ordinary & 6 & $2.1 \%$ \\
\hline \multicolumn{3}{|c|}{ Kala-azar is an important problem of disease } \\
\hline Yes & 227 & $80.2 \%$ \\
\hline No & 56 & $19.8 \%$ \\
\hline \multicolumn{3}{|c|}{$\begin{array}{l}\text { Kala-azar can be controlled through } \\
\text { community participation }\end{array}$} \\
\hline Yes & 131 & $46.3 \%$ \\
\hline No & 152 & $53.7 \%$ \\
\hline \multicolumn{3}{|c|}{ Kala-azar can affect family income } \\
\hline Yes & 252 & $89.0 \%$ \\
\hline No & 31 & $11.0 \%$ \\
\hline \multicolumn{3}{|c|}{ Kala-azar is fatal disease if it is untreated } \\
\hline Yes & 280 & $98.9 \%$ \\
\hline No & 3 & $1.1 \%$ \\
\hline \multicolumn{3}{|l|}{ Practice } \\
\hline \multicolumn{3}{|c|}{ Drug preference for treatment $V L$} \\
\hline Specific medicine & 268 & 94.7 \\
\hline Indigenous medicine & 4 & 1.4 \\
\hline Do not know & 11 & 3.9 \\
\hline \multicolumn{3}{|l|}{$\begin{array}{l}\text { Prevention measures from } \\
\text { mosquito/sand fly bite }\end{array}$} \\
\hline Use of bed net & 197 & 69.6 \\
\hline Insecticide spraying & 24 & 8.5 \\
\hline Repellents & 15 & 5.3 \\
\hline Cleanliness & 45 & 15.9 \\
\hline Do not know & 2 & .7 \\
\hline \multicolumn{3}{|l|}{ Source of information } \\
\hline Health personnel & 129 & 45.6 \\
\hline Friends and neighbours & 132 & 46.6 \\
\hline Television & 12 & 4.2 \\
\hline Magazines & 2 & .7 \\
\hline Radio & 4 & 1.4 \\
\hline School & 4 & 1.4 \\
\hline
\end{tabular}

were practicing different methods to prevent mosquitoes and other biting flies; $69.9 \%$ of the respondents used a bed net; $15.9 \%$ cleaned their environment; while $8.5 \%$ used insecticide spraying and 5.3\% used repellents (Table 3). Friends and neighbours (46.6\%) and health personnel $(45.6 \%)$ were major sources of information about kala-azar in the study area. The mass media such as television (4.2\%), radio (1.4\%) and newspapers $(0.7 \%)$ were indicated as limited information sources. Similarly the school (1.4\%) was also identified as a limited source of information (Table 3).

\section{Risk factors}

Table 4 depicts factors associated with VL transmission in univariate analysis. Factors associated with boosted VL odds were: family size in household, education level below grade five, damp house floors, cracked house walls and cracked black soil near houses. Similarly, animal ownership such as presence of cattle, owning dogs, goats and owning donkeys were found to significantly increase the odds of VL. Individual behaviour in the domestic and in the farm fields like dumping animal dung near houses, sleeping outside the house near animal shelters, sleeping under Balanites and Acacia trees at night, increased the number of days spent in the farm field and sleeping in the farm field over night was also associated with higher odds of VL risk.

On the other hand, having a separate kitchen, sleeping on a bed, sleeping outside the house under a bed net during the warm season and smoking plant parts inside and outside houses had decreased odds of VL.

Table 5 depicts factors associated with VL in multivariable conditional logistic regression models. The odds for VL consistently increased as the size of the family increased in the household (OR1.3; 95\% Cl: 1.026-1.799). Individuals who lived in a house with cracked walls had 6 times increased odds of being infected with VL compared with their counterparts (OR 6.495\% Cl; 1.585-25.580). Similarly, those who owned a goat had increased odds of a being VL case compared with those who did not own goats (OR 6.4; 95\%: $\mathrm{Cl}$ 1.5-28.4). However, daily individual activities around the home, mainly sleeping on a bed (OR 0.2; 95\%: $\mathrm{Cl} 0.03-0.9$ )], sleeping outside the house under a bed net (OR $0.093(95 \% \mathrm{Cl}$ 0.0240.357)] and smoking plant parts in the house during the night time [OR $0.082(95 \% \mathrm{Cl} 0.011-0.630)]$ were associated with decreased odds of being a VL case. Finally, the risk for VL was always elevated as the number of days spent in the farm field increased [OR 1.100 (95\% Cl 1.015-1.192)].

\section{Discussion}

Identifying the risk factors of VL infection in northwest Ethiopia offers a significant basis of information to design and develop effective control measures. There is poor knowledge, attitude and practice gap towards VL in the study area. Our results showed the presence of goats, larger family size; individual houses with cracked walls and number of days spent in the farm field were associated with increased risk of VL infection. On the other hand, daily 
Table 4 Factors associated with transmission of visceral leishmaniasis in univariate analysis

\begin{tabular}{|c|c|c|c|c|c|c|}
\hline \multirow[t]{2}{*}{ Variables } & \multirow{2}{*}{$\begin{array}{l}\text { Cases } \\
{[\mathrm{n} / \mathrm{N}(\%)]}\end{array}$} & \multirow{2}{*}{$\begin{array}{l}\text { Control } \\
\text { [n/N (\%)] }\end{array}$} & \multirow[t]{2}{*}{ OR } & \multicolumn{2}{|c|}{$95.0 \% \mathrm{Cl}$} & \multirow{2}{*}{$\begin{array}{l}P \\
\text { value }\end{array}$} \\
\hline & & & & Lower & Upper & \\
\hline \multicolumn{7}{|l|}{ Socio-demographic } \\
\hline Family size (mean, 95\% Cl)** & $5.8(5.3-6.4)$ & $4.8(4.4-5.1)$ & 1.257 & 1.110 & 1.423 & 0.000 \\
\hline Own farm land & $66(73.3 \%)$ & $140(72.5 \%)$ & 1.038 & 0.555 & 1.943 & 0.907 \\
\hline Able to read and write & $60(66.7 \%)$ & $144(74.6 \%)$ & 0.598 & 0.319 & 1.121 & 0.109 \\
\hline School grade $<5$ & $60(66.7 \%)$ & 89(46.1\%) & 3.432 & 1.760 & 6.693 & 0.000 \\
\hline \multicolumn{7}{|l|}{ Housing condition } \\
\hline Separate kitchen & $43(47.8 \%)$ & $122(63.2 \%)$ & 0.534 & 0.320 & 0.892 & 0.016 \\
\hline Animal barn inside compound & $45(50.0 \%)$ & $79(40.9 \%)$ & 0.622 & 0.350 & 1.106 & 0.106 \\
\hline Damp house floor & $24(26.7 \%)$ & $15(7.8 \%)$ & 4.328 & 2.097 & 8.932 & 0.000 \\
\hline Sleeping on bed & $74(82.2 \%)$ & 183(94.8\%) & 0.287 & 0.128 & 0.642 & 0.002 \\
\hline Thatched roof & $56(62.2 \%)$ & $113(59.5 \%)$ & 0.899 & 0.523 & 1.546 & 0.701 \\
\hline Cracked house wall & $60(66.7 \%)$ & $84(44.4 \%)$ & 2.768 & 1.549 & 4.946 & 0.001 \\
\hline Cracked black soil near house & $64(71.1 \%)$ & $60(31.1 \%)$ & 6.266 & 3.308 & 11.871 & 0.000 \\
\hline \multicolumn{7}{|l|}{ Animal ownership } \\
\hline Presence of cattle (mean, $95 \% \mathrm{Cl}$ for mean) ${ }^{* *}$ & $5.9(3.4-8.3)$ & $1.8(1.3-2.3)$ & 1.114 & 1.047 & 1.185 & 0.001 \\
\hline Dog ownership & $47(52.2 \%)$ & $48(24.9 \%)$ & 3.544 & 1.970 & 6.376 & 0.000 \\
\hline Goats ownership & $37(41.1 \%)$ & $43(22.3 \%)$ & 2.500 & 1.407 & 4.443 & 0.002 \\
\hline Number of goats per household (Mean,95\% Cl for mean)** & $4.01(2.4-5.6)$ & $2.1(1.3-3)$ & 1.041 & 1.002 & 1.083 & 0.039 \\
\hline Sheep ownership & $38(42.2 \%)$ & $72(37.3 \%)$ & 1.183 & 0.710 & 1.971 & 0.519 \\
\hline Number of sheep per household (Mean, $95 \% \mathrm{Cl}$ for mean)** & $3.9(2.1-5.6)$ & $3.4(2.4-4.5)$ & 1.006 & 0.975 & 1.038 & 0.704 \\
\hline Donkey ownership & $59(65.6 \%)$ & $98(50.8 \%)$ & 1.971 & 1.117 & 3.477 & 0.019 \\
\hline Dumping animal dung near house & $38(42.2 \%)$ & $30(15.5 \%)$ & 4.170 & 2.215 & 7.849 & 0.000 \\
\hline Apply insecticide to livestock & $21(23.3 \%)$ & $64(33.2 \%)$ & 0.603 & 0.339 & 1.072 & 0.085 \\
\hline \multicolumn{7}{|l|}{ Individual activities } \\
\hline Sleeping outside the house near animal shelter & $43(47.8 \%)$ & $46(23.8 \%)$ & 3.062 & 1.725 & 5.437 & 0.000 \\
\hline Sleeping under Balanites-acacia trees at night & $64(71.1 \%)$ & $96(49.7 \%)$ & 2.613 & 1.453 & 4.702 & 0.001 \\
\hline Sleeping outside the house under bed net & $16(17.8 \%)$ & $118(61.1 \%)$ & 0.130 & 0.066 & 0.258 & 0.000 \\
\hline House sprayed with insecticides & $16(17.8 \%)$ & $49(25.5 \%)$ & 0.577 & 0.290 & 1.148 & 0.117 \\
\hline Smoking house & $50(56.2 \%)$ & $168(87.0 \%)$ & 0.093 & 0.038 & 0.225 & 0.000 \\
\hline \multicolumn{7}{|l|}{ Period of days stayed in the farm field } \\
\hline Mean ( $95 \% \mathrm{Cl}$ for mean)** & $91.3(61.7-120.9)$ & $8(5.9-10)$ & 1.035 & 1.009 & 1.062 & 0.008 \\
\hline Sleeping in the farm field over night & $66(76.7 \%)$ & $109(56.5 \%)$ & 4.159 & 1.745 & 9.913 & 0.001 \\
\hline
\end{tabular}

Odd ratios (OR), 95\% confidence intervals $(\mathrm{Cl})$, and $\mathrm{P}$ values derived from univariate conditional logistic regression models. ${ }^{* *}$ refers to calculated means.

individual behaviour in the domestic and natural habitat; mainly sleeping on a bed, sleeping outside the house with a bed net and smoking plant parts in the house at night time were associated with reduced risk of VL infection. The results here were in conformity with previous studies [22-34].

A total of 1128 (1019 males: 109 females) VL patients were admitted at Kahsay Abera Hospital during the period of July 2011 and August 2013. These patients came from different districts of northwest Ethiopia; mainly from Setit Humera, Kafta Humera, Welkayit and Tsegede. From the data, more male patients were seen than female patients, with a male to female ratio of 9:1. A similar result was reported in Gondar and Axum hospitals [35,36]. This high male patient load could be due to the economic activities that entail gender bias. Previous studies documented that males are disproportionately affected by VL compared to females, this is mainly related to their work (agricultural activities, keeping animals, daily labourer and soldiers) $[35,36]$.

The present study revealed that VL case load in the hospital peaked during January and February, the dry 
Table 5 Factors associated with VL in a 'multivariate conditional logistic regression model among the community in Northwest Ethiopia

\begin{tabular}{|c|c|c|c|c|}
\hline Variables & $\begin{array}{l}\text { Cases } \\
\text { No. (\%) }\end{array}$ & $\begin{array}{l}\text { Controls } \\
\text { No. (\%) }\end{array}$ & $\begin{array}{l}\text { Adjusted OR ratio } \\
(95 \% \mathrm{Cl})\end{array}$ & $\begin{array}{l}P \\
\text { value }\end{array}$ \\
\hline Family size (mean 95\% Cl) & $5.8(5.3-6.4)$ & $4.8(4.4-5.1)$ & $1.359(1.026-1.799)$ & 0.032 \\
\hline Sleeping on bed & $74(82.2 \%)$ & $183(94.8 \%)$ & $0.158(0.028-0.898)$ & 0.037 \\
\hline Ref. ground & $16(17.8 \%)$ & $10(5.2 \%)$ & 1 & \\
\hline Cracked house wall (Yes) & $60(66.7 \%)$ & $84(44.4 \%)$ & $6.368(1.585-25.580)$ & 0.009 \\
\hline Ref. (un-cracked) & $30(33.3 \%)$ & $105(55.6 \%)$ & 1 & \\
\hline Own goats (Yes) & $37(41.1 \%)$ & $43(22.3 \%)$ & $6.445(1.463-28.384)$ & 0.014 \\
\hline Ref. (No) & $53(58.9 \%)$ & $150(77.7 \%)$ & 1 & \\
\hline Sleeping outside the house under bed net & $16(17.8 \%)$ & $118(61.1 \%)$ & $0.093(0.024-0.357)$ & 0.001 \\
\hline Ref. (without bed net) & $74(82.2 \%)$ & $75(38.9 \%)$ & 1 & \\
\hline Smoking house (Yes) & $50(56.2 \%)$ & $168(87.0 \%)$ & $0.082(0.011-0.630)$ & 0.016 \\
\hline Ref. (No) & $39(43.8 \%)$ & $25(13.0 \%)$ & 1 & \\
\hline Number of days stayed in the farm field (mean 95\% CL) & $91.3(61.7-120.9)$ & $8(5.9-10)$ & $1.100(1.015-1.192)$ & 0.020 \\
\hline
\end{tabular}

Odd ratios (OR), 95\% confidence intervals $(\mathrm{Cl})$, and $\mathrm{P}$ values derived from multivariable conditional logistic regression models.

season in the area. This was consistent with the agricultural labourer movement that peaks during the period June-November. In south Ethiopia, a high number of VL patients were diagnosed during August to November (rainy season) [37]. The VL transmission seasons (months) in Kafta Humera lowlands have not yet been delineated. However, its transmission may be associated with the abundance of sand flies in the area (March, April, May and early June) [Yared et al., unpublished]. Higher number of VL cases were recorded above 14 years of age group, which is in contrast to another study in South Sudan, where $56 \%$ of the cases were under 5 years old [38].

Almost all the study participants identified or have heard of VL. This is in agreement with studies conducted elsewhere in endemic communities [39-41]. The current study area has been known to be endemic for VL for more than four decades [12]. However, only a few of participants knew the mode of transmission and recognized the vector. Besides, only $7.4 \%$ of the participants knew the correct breeding sites of sand fly vectors in the area. However, recent study showed that cracked vertisols were identified as breeding site of $P$. orientalis and other sand flies in northwest Ethiopia [18]. As a result our observation indicated that enhancing awareness about specific breeding habitats of sand flies and mode of VL transmission are very vital to reduce the transmission of the infection.

In this study, owning goats was associated with elevated VL risk. Perhaps goats play no role as reservoirs of $L$. donovani, but they may attract the vector to human houses and thereby increase the risk of human exposure to infected sand flies. In the present study area, entomological studies showed that $P$. orientalis (the presumed vector of VL in north Ethiopia) has a feeding preference to domestic animals [16]. Similarly, owning domestic animals (cows, buffaloes or goats) was associated with a higher risk of being DAT positive VL elsewhere $[23,30,32,33,42-44]$. Another study in Ethiopia (Libo Kemekem district) has revealed that dog ownership in the villages was a significant risk factor for VL [11]. Studies carried out in Nepal and Bangladesh, found out that ownership of large domestic animals such as cattle and water buffalo was strongly protective [22,24]. On the other hand, a case-control study in Bihar (India) found no significant associations between VL and keeping domestic animals inside the house or ownership of domestic animals [30]. Thus, different studies in different endemic countries have reported different or similar domestic animals as either risk factors or protective. This could be due to the variation of geographical location, the abundance of the host, the abundance, feeding preference, breeding habitat and resting site of the vector and the leishmanial infection rate.

We found a very strong association between VL and poor housing conditions, such as cracked house walls. Cracked walls could be made through drying and could be used as ideal breeding and resting sites of sand flies. We collected $P$. orientalis from the exterior cracked wall of houses using sticky traps in the villages (Yared et al. unpublished). Our study confirmed individuals who are sleeping regularly near the cracked walls are at higher risk of VL. In southern Ethiopia, an un-plastered house was a major individual risk factor [45]. Similarly in Nepal, houses constructed in mud and thatched with a damp floor were associated with elevated risk of VL $[22,26,34]$. In India, mud-plastered walls in houses and houses not sprayed with DDT in the past six months were significant risk factors for kala-azar [25,30]. In 
India and Kenya $[27,29]$ mud plastered wall, mixed dwelling and cattle shed were found to be ideal environments for phlebotomine sand flies.

The final logistic regression model in the present analysis revealed larger family size in the household was associated with elevated VL risk. Two studies in Nepal agree with our result $[26,34]$. This could be due to the increasing amount of carbon dioxide and odours released in the homestead that attract a large number of sand flies. Similar to previous studies [22,34], our results showed sleeping on a bed was more protective as compared to sleeping on the ground. Studies indicated that sand flies emerge from the cracked vertisol [18] and move in short hops and fly close to the ground [46]. It also indicated that the risk for VL increased as the number of days spent in the farm fields increased. $P$. orientalis was found to be abundant in the farm fields (Yared et al., unpublished) and this may indicate VL transmission occurs outside of the villages. In Nepal, a regular forest visit was also associated with elevated VL odds [34]. Put together, these findings are highly indicative of the need for policy makers to devise control methods not only in the villages, but in the farm fields as well.

Bed nets were associated with protection of VL in Bangladesh and Nepal [22,24]. A case control study in East Africa has also revealed that owning a mosquito net was associated with a reduced risk of VL [28]. Similarly our result confirmed that sleeping outside houses under bed nets was associated with decreased VL risk. Use of a bed net is significantly important to bar the transmission cycle of $L$. donovani infection from sand fly to human. During the dry season, almost all individuals in the communities sleep outside the house due to the hot weather conditions. Sand flies were also abundant during this time when collected from the vicinity of the villages in the cracked black soil and periphery of villages (Yared et al., unpublished). Long lasting insecticide treated nets (LLINs) were distributed by the government and are also commercially available. Bed nets that were not impregnated with insecticide or in poor condition were not protective [26]. Thus bed nets should be impregnated with insecticide in order to enhance its protectiveness.

Smoking plant parts in the house during the night time was associated with strong protection. The villagers, especially during the rainy season, commonly practiced smoking to repel mosquitoes and other night active flies, using wood of Weyiba (a Tigrigna term for Terminalia brownii -Combretaceae) inside and outside the house. However, its repellent activities against biting insects, have not been evaluated, and need further investigation. This species is a medicinal plant with antiplasmodial and antimicrobial activities [47]. Due to the exophagic and crepuscular behaviour of $P$. orientalis, LLINs may provide incomplete protection from bites [16]. Complementary control methods, such as repellents, are very vital where vectors are exophagic. Natural repellents such as neem and chinaberry seed oils are grown widely in the region and could be ideal and cheaper repellents [48]. They can be applied to people who work outdoors at night when the sand fly biting peaks, either during early evenings before people retire to bed or when people sleep outside their houses during the warmer seasons and while harvesting at night time.

The major strength of this study was the matching of cases with two controls; taking sex, age group, migration and location as matching variables. Misclassification bias is low since both cases and controls were selected after proper diagnostic tests were performed. We collected blood samples from all controls and tested using DAT to identify asymptomatic Leishmanial infection in the control group. However, this study is not without limitation. First income was not measured, because they didn't know their own monthly and annual income. In addition, we didn't consider the nutritional status of the respondents. Despite the limitations mentioned here we found very strong indicators of risk factors for VL and these variables would be pivotal for designing appropriate control measures.

These findings have important practical implications because several relevant features that will help to understand VL transmission dynamics have been elucidated. Besides, this study will be helpful for designing and developing effective control methods. It is also supportive for the policy maker to disseminate knowledge at individual and community level and to develop a systematic way of implementing control methods. Future studies considering risk factors of VL should include nutritional status and presence of other animals such as rodents. Additionally, future studies should investigate the risk factors of $\mathrm{VL}$ vectors biting at individual level as well as the association with density of phlebotomine sand flies and with the incidence of $L$. donovani infection in human. Finally, future studies should investigate whether these findings are consistent or not.

\section{Conclusion}

In conclusion, we found owning goats, living in houses with cracked walls, large family size and number of days spent in the farm were associated with increased VL risk. In contrast, sleeping on a bed, sleeping outside houses under bed nets and use of smoke at night time was associated with decreased odds of VL. Our findings have implications for planning and control of VL. Firstly, individual protective measures such as use of bed net and smoke could easily be adopted for the prevention of VL in the area particularly among individuals who spend most of their time in the field; and secondly improving housing conditions such as removing cracks from houses would help to reduce risk of VL. There are also research questions to be answered; first, the association of goat 
ownership and risk of VL should be investigated in detail, second, the repellent effect of the traditional smokes used in the area should be evaluated, and third the effectiveness of available bed nets for prevention of VL should be evaluated.

\section{Competing interests}

The authors declare that they have no competing interests.

\section{Authors' contributions}

Conceived and designed the study: SY, KD, AH. Performed data collection and questionnaire development: SY, AG, WL, EA, OK, AM. Analyzed the data and interpretation the results: SY, KD, AH, TGM, AW. Wrote the paper: SY, KD, MB, AH, TGM, AW. All authors read and approved the final manuscript.

\section{Acknowledgements}

This study was supported by Bill and Melinda Gates Foundation Global Health Program (grant number OPPGH5336). KD is supported by the Wellcome Trust Fellowship in Public Health and Tropical Medicine [grant number 099876]. We gratefully acknowledge Nurse Seltan Gebreselassie, and laboratory technician Shumuye Hagos for their assistance with collection of blood samples and separating serum at Setit Humera Health Centre. We thank Mokennen Arefaiene (head of Adebay Health centre) and Berhe Gebremeskel for identifying VL patients based on their address as well as cooperating and performing the questionnaires. We also thank Welelta Shiferaw and Asrat Bezuneh for their assistance in testing the blood samples using DAT. The Aklilu Lemma Institute of Pathobiology and Department of Medical Microbiology, Immunology and Parasitology, Faculty of Medicine, Addis Ababa University are acknowledged for allowing and supporting the study. Finally, we warmly thank the participants of the study and Kahsay Abera Hospital ward section for availing VL data.

\section{Author details}

1Aklilu Lemma Institute of Pathobiology, Addis Ababa University, Addis Ababa, Ethiopia. ${ }^{2}$ Department of Biology, College of Natural Science, Jigjiga University, Jigjiga, Ethiopia. ${ }^{3}$ Brighton \& Sussex Medical School, Falmer, Brighton, UK. ${ }^{4}$ School of Public Health, Addis Ababa University, Addis Ababa, Ethiopia. ${ }^{5}$ Department of Zoological Science, Addis Ababa University, Addis Ababa, Ethiopia. ${ }^{6}$ Department of Microbiology and Molecular Genetics, The Institute of Medical Research Israel-Canada The Kuvin Center for the Study of Infectious and Tropical Diseases, Faculty of Medicine, The Hebrew University, Hadassah Medical School, Jerusalem, Israel. ${ }^{7}$ Department of Microbiology, Immunology and Parasitology, Faculty of Medicine, Addis Ababa University, Addis Ababa, Ethiopia.

Received: 4 July 2014 Accepted: 1 October 2014

Published online: 14 October 2014

\section{References}

1. Alvar J, Vélez ID, Bern C, Herrero M, Desjeux P, Cano J, Jannin J, Den Boer M, WHO Leishmaniasis Control Team: Worldwide and global estimates of its incidence. PLoS One 2012, 7:e35671.

2. Ngure PK, Kimutai A, Ng'ang'Z W, Rukunga G, Tonui WK: A review of leishmaniasis in Eastern Africa. JNMU 2009, 23:79-86.

3. Anema A, Ritmeijer K: Treating HIV/AIDS and leishmaniasis co-infection in Ethiopia. JAMC 2005, 172:1434-1435.

4. Hailu A, Gebre-Michael T, Berhe N, Balkew M: Leishmaniasis. In Epidemiology and Ecology of Health and Disease in Ethiopia. 1st edition. Edited by Kloos $\mathrm{H}$, Berhane Y, Hailemariam D. Addis Ababa, Ethiopia: Shama Books; 2006:556-576.

5. Deribe K, Meribo K, Gebre T, Hailu A, Ali A, Aseffa A, Davey G: The burden of neglected tropical diseases in Ethiopia, and opportunities for integrated control and elimination. Parasit Vectors 2012, 5:240.

6. Tsegaw T, Gadisa E, Seid A, Abera A, Teshome A, Mulugeta A, Herrero M, Argaw D, Jorge A, Aseffa A: Identification of environmental parameters and risk mapping of visceral leishmaniasis in Ethiopia by using geographical information systems and a statistical approach. Geospat Health 2013, 7:299-308.

7. Fuller GK, Lemma A, Haile T, Gemeda N, Kala-azar in Ethiopia: survey of south-west Ethiopia. The Leishmanin skin test and epidemiological studies. Ann Trop Med Parasitol 1979, 73:417-430.
8. Ayele T, Ali A: The distribution of visceral leishmaniasis in Ethiopia. Am J Trop Med Hyg 1984, 33:548-552.

9. Alvar J, Bashaye S, Argaw D, Cruz I, Aparicio P, Kassa A, Orfanos G, Parreño F, Babaniyi O, Gudeta N, Cañavate C, Bern C: Kalaazar outbreak in Libo Kemkem, Ethiopia: epidemiologic and parasitologic assessment. Am J Trop Med Hyg 2007, 77:275-282.

10. Hailu A, Gramiccia M, Kager PA: Visceral leishmaniasis in Aba-Roba, south-western Ethiopia: prevalence and incidence of active and subclinical infections. Ann Trop Med Parasitol 2009, 103:659-670.

11. Bashaye S, Nombela N, Argaw D, Mulugeta A, Herrero M, Nieto J, Chicharro C, Cañavate C, Aparicio P, Vélez ID, Alvar J, Bern C: Risk factors for visceral leishmaniasis in a new epidemic site in Amhara Region, Ethiopia. Am J Trop Med Hyg 2009, 81:34-39.

12. Tekle A, Neri D, Debessai A: Kalaazar in Humera (north-west Ethiopia). Parassitologia 1970, 72:21-25

13. Mengesha B, Abuhoy M: Kala-azar among labour migrants in Metema-Humera region of Ethiopia. Trop Geogr Med 1978, 30:199-206.

14. Seblova V, Volfova V, Dvorak V, Pruzinova K, Votyapka J, Kassahun A, Gebre-Michael T, Hailu A, Warburg A, Volf P: Phlebotomusorientalis sandflies from two geographically distant Ethiopian localities: biology, genetic analyses and susceptibility to Leishmaniadonovani. PLoSNegl Trop Dis 2013, 7:e2187.

15. Elnaiem DA, Ward RD, Hassan HK, Miles MA, Frame IA: Infection rates of Leishmaniadonovani in Phlebotomusorientalis from a focus of visceral leishmaniasis in eastern Sudan. Ann Trop Med Parasitol 1998, 92:229-232.

16. Gebre-Michael T, Balkew M, Berhe N, Hailu A, Mekonnen Y: Further studies on the phlebotominesandflies of the kala-azar endemic lowlands of Humera- Metema (North-West Ethiopia) with observations on their natural blood meal sources. Parasit Vectors 2010, 3:6.

17. Elnaiem DA, Connor SJ, Thomson MC, Hassan MM, Hassan HK, Aboud MA, Ashford RW: Environmental determinants of the distribution of Phlebotomusorientalis in Sudan. Ann Trop Med Parasitol 1998, 92:877-887.

18. Moncaz A, Kirstein O, Gebresellassie A, Lemma W, Yared S, Gebre-Michael T, Hailu A, Shenker M, Warburg A: Characterization of breeding sites of Phlebotomusorientalis-The vector of visceral leishmaniasis in northwestern Ethiopia. Acta Trop 2014, 139C:5-14.

19. Haileselassie B, Ali A: Assessment of insecticide treated nets coverage for malaria control in Kafta-Humera district, Tigray: Possession versus use by high-risk groups. Ethiop. J Health Dev 2008, 22:259-267.

20. Gemetchu T, Zerihune A, Assefa G, Lemma A: Observations on the sandfly (phlebotomidae) fauna of Setit Humera (Northwestern Ethiopia). Ethiop Med J 1975, 13:41-51.

21. ter Horst R, Tefera T, Assefa G, Ebrahim AZ, Davidson RN, Ritmeijer K: Field evaluation of rK39 test and direct agglutination test for diagnosis of visceral leishmaniasis in a population with high prevalence of human immunodeficiency virus in Ethiopia. Am J Trop Med Hyg 2009, 80:929-934.

22. Bern C, Joshi AB, Jha SN, Das ML, Hightower A, Thakur GD, Bista MB: Factors associated with visceral leishmaniasis in Nepal: bed-net use is strongly protective. Am J Trop Med Hyg 2000, 63:184-188.

23. Mukhtar MM, Sharief AH, el Saffi SH, Harith AE, Higazzi TB, Adam AM, Abdalla HS: Detection of antibodies to Leishmaniadonovani in animals in a kala-azar endemic region in eastern Sudan: a preliminary report. Trans R Soc Trop Med Hyg 2000, 94:33-36.

24. Bern C, Hightower WA, Chowdhury R, Ali M, Amann J, Wagatsuma Y, Haque R, Kurkjian K, Vaz EL, Begum M, Akter T, Cetre-Sossah BC, Ahluwalia Bl, Secor $D E$, Breiman FR, Maguire HJ: Risk Factors for Kala-Azar in Bangladesh. Emerg Infect Dis 2005, 11:655-662.

25. Ranjan A, Sur D, Singh VP, Siddique NA, Manna B, Lal CS, Sinha PK, Kishore K, Bhattacharya SK: Risk factors for Indian kala-azar. Am J Trop Med Hyg 2005, 73:74-78.

26. Schenkel K, Rijal S, Koirala S, Koirala S, Vanlerberghe V, Van der Stuyft P, Gramiccia M, Boelaert M: Visceral leishmaniasis in southeastern Nepal: a cross-sectional survey on Leishmaniadonovani infection and its risk factors. Trop Med Int Health 2006, 11:1792-1799.

27. Ryan JR, Mbui J, Rashid JR, Wasunna MK, Kirigi G, Magiri C, Kinoti D, Ngumbi PM, Martin SK, Odera SO, Hochberg LP, Bautista CT, Chan AS: Spatial clustering and epidemiological aspects of visceral leishmaniasis in two endemic villages, Baringo District, Kenya. Am J Trop Med Hyg 2006, 74:308-317.

28. Kolaczinski JH, Reithinger R, Worku DT, Ocheng A, Kasimiro J, Kabatereine N, Brooker S: Risk factors of visceral leishmaniasis in East Africa: a case-control 
study in Pokot territory of Kenya and Uganda. Int J Epidemiol 2008, 37:344-352.

29. Kesari S, Bhunia GS, Kumar V, Jeyaram A, Ranjan A, Das P: Study of house-level risk factors associated in the transmission of Indian Kala-azar. Parasit Vectors 2010, 3:94.

30. Khanal B, Picado A, Bhattarai NR, Van Der Auwera G, Das ML, Ostyn B, Davies CR, Boelaert M, Dujardin JC, Rijal S: Spatial analysis of Leishmaniadonovani exposure in humans and domestic animals in a recent kala azar focus in Nepal. Parasitology 2010, 137:1597-1603.

31. Singh SP, Hasker E, Picado A, Gidwani K, Malaviya P, Singh RP, Boelaert M, Sundar S: Risk factors for visceral leishmaniasis in India; Further evidence on the role of domestic animals. Trop Med Int Health 2010, 15:29-35.

32. Singh SP, Picado A, Boelaert M, Gidwani K, Andersen EW, Ostyn B, Meheus F, Rai M, Chappuis F, Davies C, Sundar S: The epidemiology of Leishmaniadonovani infection in high transmission foci in India. Trop Med Int Health 2010, 15:12-20.

33. Khatun M, Rahim MA, Huda M, Haider N, Ghosh D, Mondal D: Serological Evidence of Visceral Leishmaniasis (VL) among Goats in VL Endemic Areas of Bangladesh, International Society for Infectious Diseases 2012, 15th International congress on Infectious diseases, Bangok, Thailand, June 13-16 2012, Centara Grand \&Bangkok Convention Centre at Central World, 15: [Abstract]. http://www.xcdsystem.com/icid_ise2012/ISE.279.html.

34. Uranw S, Hasker E, Roy L, Meheus F, Das ML, Bhattarai NR, Rijal S, Boelaert M: An outbreak investigation of visceral leishmaniasis among residents of Dharan town, eastern Nepal, evidence for urban transmission of Leishmaniadonovani. BMC Infect Dis 2013, 13:21.

35. Haile T, Anderson SD: Visceral Leishmaniasis in Northern Ethiopia. East Afr Med J 2006, 83:389-392.

36. Mengistu G, BeleteAyele B: Visceral Leishmaniasis and HIV co-infection in patients admitted to Gondar university hospital, northwest Ethiopia. EthiopJHealth Dev 2007, 21:53-60.

37. Lindtjørn B: Kala-azar in south-west Ethiopia: seasonal variation in disease occurrence. Trans R Soc Trop Med Hyg 1984, 78:790-791.

38. Nyunguraa $J L$, Nyambatib VCS, Muitac M, Eric Muchirid E: Risk factors for the transmission of kala-azar in Fangak, South Sudan. SSMJ 2011, 4:26-29.

39. Medicines Sans Frontiers: Perception of Kalazar among Pokot Communities in Amudat, Uganda. Swizzerland: Final report by Epicenter and MSF; 2002:348-349.

40. Mondal D, Singh SP, Kumar N, Joshi A, Sundar S, Das P, Siddhivinayak H, Kroeger A, Boelaert M: Visceral leishmaniasis elimination programme in India, Bangladesh, and Nepal: reshaping the case finding/case management strategy. PLoSNegl Trop Dis 2009, 3:e355.

41. Alemu A, Esmael N, Dessie Y, Hamdu K, Mathewos B, Birhan W: Knowledge, attitude and practices related to visceral leishmaniasis among residents in Addis Zemen town, South Gondar, Northwest Ethiopia. BMC Public Health 2013, 13:382.

42. Bhattarai NR, Van der Auwera G, Rijal S, Picado A, Speybroeck N, Khanal B, De Doncker S, Das ML, Ostyn B, Davies C, Coosemans M, Berkvens D, Boelaert M, Dujardin JC: Domestic animals and epidemiology of visceral leishmaniasis, Nepal. Emerg Infect Dis 2010, 16:231-237.

43. Singh N, Mishra J, Singh R, Singh S: Animal reservoirs of visceral leishmaniasis in India. J Parasitol 2013, 99:64-67.

44. Williams AO, Mutinga J, Rodgers M: Leishmaniasis in a domestic goat in Kenya. Mol Cell Probes 1991, 5:319-325.

45. Ali A: Visceral leishmaniasis in southern Ethiopia: I. Environmental and behavioural risk factors. Ethiop J Health Dev 1997, 11:131-137.

46. Quate LW: Phlebotomus sandflies of the Paloich area in the Sudan (Diptera, Psychodidae). J Med Ent 1964, 3:213-268.

47. Machumi F, Midiwo OJ, Jacob M, Khan IS, Tekwani LB, Walker L, Muhammad I: Phytochemical, Antiparasitic and Antimicrobial Investigations of Terminalia brownie, The 15th NAPRECA Symposium 7-10th Dec. 2013. Khartoum, Sudan, 15:42-43[Abstract].

48. Kebede Y, TeshomeGebre-Michael T, Balkew M: Laboratory and field evaluation of neem (AzadirachtaindicaA. Juss) and Chinaberry (Meliaazedarach L.) oils as repellents against Phlebotomusorientalis and $P$. bergeroti (Diptera: Psychodidae) in Ethiopia. Acta Trop 2010, 113:145-150.

\section{Submit your next manuscript to BioMed Central and take full advantage of:}

- Convenient online submission

- Thorough peer review

- No space constraints or color figure charges

- Immediate publication on acceptance

- Inclusion in PubMed, CAS, Scopus and Google Scholar

- Research which is freely available for redistribution 